\title{
Effect of Different Impellers and Baffles on Aerobic Stirred Tank Fermenter using Computational Fluid Dynamics
}

\author{
Sharma Alok ${ }^{1}$ and Genitha Immanuel ${ }^{2}$ \\ ${ }^{1}$ Food Technology (Food Process Engineering), SHIATS, Allahabad, India \\ ${ }^{2}$ Department of Food Process Engineering, SHIATS, Allahabad, India
}

\begin{abstract}
The present research was carried out with objective to study the effect of different types of Impellers and Baffles on mixing and to examine the correlation between mixing time and mass transfer of Aerobic Stirred Tank Fermenter An Aerobic Stirred Tank fermenter was assembled with different Impellers and Baffles alternately. The four different Impellers used were Rushton Impeller, Marine Impeller, A320 Impeller and HE3 Impeller while walled and un walled baffles were used in combination with these Impellers. The Fermenter was assembled with Resistance Temperature Detector, pH Probe and Pressure Gauge. Tachometer was used to calculate the Mixing Time of Fermenter. Volumetric Mass Transfer Coefficient was experimentally determined and calculated by the respective formulae. MATLAB was used for Mathematical Modelling of CFD, while Autodesk Simulation CFD and ANSYS FLUENT were used to generate the simulations. Turbulence lengths and Trailing Vortices were used to understand flow patterns inside the fermenter created by Impellers and Baffles. The $\mathrm{k}_{\mathrm{L}} \mathrm{a}$ values suggested that Rushton Impeller was the most efficient among all. Turbulent Kinetic Energy and Turbulent Dissipation Rate were to understand the mixing efficiency of every Impeller.
\end{abstract}

Keywords: CFD; Aerobic stirred tank fermenter; Turbulent kinetic energy; Turbulent; Dissipation rate

\section{Introduction}

Fermentation is the conversion of carbohydrates to alcohols and carbon dioxide or organic acids using desirable microorganisms. The fermentation is carried out in specially designed and engineered device or system called fermenter [1,2]. The class of fermenters varies in a wide range according to the requirement of process to be carried out. They have the following functions: homogenization, suspension of solids, dispersion of gas-liquid mixtures, aeration of liquid and heat exchange. It is provided with a baffle and a rotating stirrer attached either at the top or at the bottom of the fermenter [3].

The typical decision variables are type, size, and location impellers and baffles. These determine the hydrodynamic pattern in the reactor, which in turn influence mixing time, mass and heat transfer coefficients, shear rates etc. [4-7]. The conventional fermentation is carried out in a batch mode. Since stirred tank reactors are commonly used for batch processes with slight modifications, these reactors are simple in design and easier to operate. The batch stirred tanks generally suffer due to their low volumetric productivity. The Stirred tank reactor offers excellent mixing and reasonably good mass transfer rates. The cost of operation is lower and the reactors can be used with a variety of microbial species $[8,9]$.

A research team led by Chaim Weizmann in Great Britain during the First World War developed a process for the production of acetone by a deep liquid fermentation using Clostridium acetobutylicum which led to the eventual use of the first truly large scale aseptic fermentation vessels $[10,11]$. The fermenters consisted of large cylindrical tanks with air introduced at the base via networks of perforated pipes. Later, mechanical impellers were used to increase the mixing rate and to breakup and disperse the air bubbles. Baffles on the walls of vessels prevented a vortex formation in fermentation broth [12]. In 1932, a system was introduced in which aeration tubes were provided with water and steam for cleaning and sterilizing. Construction work on the first large scale plant to produce penicillin by deep fermentation was started in September 1943, at Terre Haute in the United States of
America, building steel fermenters with working volumes of 54,000 $\mathrm{dm}^{3}[13]$.

In food processing industries, the fermentation is very important for various products e.g. alcoholic beverages, organic acids (acetic acid, citric acid etc.). Today's fermenters are more sophisticated as reflected by the various monitoring and control facilities with computer interfere for a more efficient fermentation process while the hardware remains the same [14]. The main function of a fermenter is to provide a controlled environment for the growth of microorganisms to get the desired product as like adequate aeration and agitation, low power consumption, temperature and $\mathrm{pH}$ control, minimum labor requirement and economy. In aerobic fermenters the dissolution of oxygen to the fermentation broth is important for the efficient operation of reactor $[15,16]$. Traditionally, stirred tank design is driven by the oxygen transfer capability needed to achieve cell growth. However, design methodologies available for stirred tank fermenters are insufficient and many times contains errors [17].

The most difficult part of the design is matching the fermenter capability to the oxygen demand of the fermentation culture. Some general guidelines have been offered on how to improve mass transfer in stirred tank reactors. In addition some correlations have been formed to provide predictions on stirred tank performance. However, the guidelines offered do not provide information on how different aspects of the tank (i.e. impeller and baffle geometry) specifically effect oxygen transfer in stirred tanks. The correlations offered do not provide

*Corresponding author: Sharma Alok, M. Tech, Food Technology (Food Process Engineering), SHIATS, Allahabad, India, Tel: 91-786-972-0335; E-mail: bioboy.alok@gmail.com

Received August 15, 2014; Accepted November 03, 2014; Published November 07, 2014

Citation: Alok S, Immanuel G (2014) Effect of Different Impellers and Baffles on Aerobic Stirred Tank Fermenter using Computational Fluid Dynamics. J Bioprocess Biotech 4: 184 doi: 10.4172/2155-9821.1000184

Copyright: (c) 2014 Alok S, et al. This is an open-access article distributed under the terms of the Creative Commons Attribution License, which permits unrestricted use, distribution, and reproduction in any medium, provided the original author and source are credited. 
a wide enough range of tank sizes, power inputs or gas flow rates to be useful to more than just a handful of people. In addition the efficacy of different baffle and impeller types in STRs were assessed. This was accomplished through four key areas. First, empirical studies were used to quantify the mass transfer capabilities of several different reactors; second, Computational Fluid Dynamics (CFD) was used to assess the impact of certain baffle and impeller geometries; third, correction schemes were developed and applied to the experimental data; and fourth, dimensionless correlations were created to act as a guide for future production scale fermenter design [18-22].

The CFD analysis of this research work was based on Turbulence Modelling of the fermenter. Turbulence modelling is construction and use of a model to predict the effects of turbulence [23]. Among these Reynolds-averaged Navier Stokes equation and $\kappa-\varepsilon$ models were mainly used for the mathematical modelling of fermenter. These equations provided the outcome of the modelling of fermenter and the experimental data were evaluated accordingly. In light of above discussion, a study on the effect of different Impellers and Baffles was undertaken with the following objectives

1. To study the effect of different types of impeller and baffle on mixing of aerobic stirred tank fermenter.

2. To examine the possibility of a correlation between mixing time and mass transfer in aerobic stirred tank fermenter.

\section{Material and Methods}

The present study was carried out in Faculty of Agriculture Engineering, Indira Gandhi Agriculture University, Raipur. The experimental plan of present study is presented in Table 1 . The materials required for this study were Aerobic Stirred Tank F e r m e $\mathrm{n} \mathrm{t}$ e $\mathrm{r}$, Impellers (i.e. Rushton Impeller, Marine Impeller, A320 Impeller and HE3 Impeller), Baffles (Walled and Unwalled)

\section{Design calculations}

The most popular range of ratio of height to diameter is $1: 1$ to $3: 1$ for stirred tank fermenters. In this project the ration of height (h) is diameter (D) is taken as 2:1. The diameter of the vessel was $0.50 \mathrm{~m}$ and the height of vessel was $1.00 \mathrm{~m}$.

Hence, the calculated volume of the fermenter was $0.1964 \mathrm{~m}^{3}$ or $196.35 \mathrm{~L}$. The working volume of fermenter was calculated to be $75 \%$ of the total volume. The impeller diameter must be one-third to the vessel diameter. So, the impeller diameter was calculated as $0.167 \mathrm{~m}$. The pitch between impeller and vessel bottom was taken equal to impeller diameter i.e. $0.167 \mathrm{~m}$. The length of impeller blade must be one-fourth of impeller diameter and calculation showed it $0.042 \mathrm{~m}$. The width of impeller must be one-fifth of impeller diameter, after calculating it was $0.035 \mathrm{~m}[24-26]$.

\section{Assembling of impellers and baffles}

This step involved the assembling all parts of the fermenter. The vessel body was already fitted with the baffles and discharge port. The drive motor was installed on the cover plate of fermenter using J-bolts and oil spill. J-bolts were used to support and hold the motor while the oil spill was used to ensure that there is no leakage or air passage from the entry point of drive shaft [27-30]. A coupling was used to facilitate the changing of impeller assembled with drive shaft. A port was provided for feed inlet at the cover plate. Similarly, a port was made to facilitate the air inlet in the fermenter. A port was made to fit the thermometer inside the fermenter. A pressure gauge was installed along with air emergency air outlet. $O$ rings and gaskets were used at all the ports to avoid any kind of air leakage and contamination inside and outside of the fermenter. A spray ball was fitted at the inside-top of the fermenter to facilitate the cleaning and sterilization of fermenter.

\section{Processing}

The processing was done by running the fermenter with cane juice. The cane juice was collected from the local market. 18L of cane juice was used as feed for the fermenter. After filling the fermenter with cane juice, the fermenter was closed tightly (air tight). Then it was allowed to run, during this process the required data was obtained and the processing was regularly monitored. The temperature was about $37^{\circ} \mathrm{C}[31]$.

\section{Performance evaluation}

The performance evaluation of aerobic stirred tank fermenter was done by using various software packages i.e. MATLAB 8.01, Autodesk Simulation CFD and ANSYS FLUENT. The mathematical modelling was done by using MATLAB 8.01. It is the fourth generation programming language tool. Mathematical equations like Reynolds averaged Navier Stokes equation were programmed with proper inputs, which finally calculated the output of the process. Turbulence modelling method of Computational Fluid Dynamics was used for mathematical modelling. The models used were $\kappa-\varepsilon$ model, $\kappa-\omega$ model, Shear Stress Transport model (SST) and Scale Adaptive Simulation SST (SAS-SST). All the data generated by these models were implemented in Autodesk Simulation CFD and ANSYS FLUENT software packages [32-34]. These software packages showed the results in various simulations. Simulation was preferred because it becomes very easy to understand the complex conclusion of CFD equations. These simulations were showing various coloured patterns of the fermenter performance. Results were obtained for both impellers i.e. Rushton turbine and Paddle impeller. In the k- $\varepsilon$ model the turbulent kinetic energy $\mathrm{k}$ and its rate of dissipation $\varepsilon$ are obtained from the transport equations.

Fluent used two approaches to modelling this "near-wall" region. The wall function approach bridges the viscosity-affected region between the wall and the fully turbulent region. The turbulence lengthscales used in this study are given for the k- $\varepsilon$ and SSG-RSM model and for the SST and SAS-SST models [35].

\section{Experimental determination of volumetric mass transfer coefficient}

For this method first the water in the tank is deoxygenated by sparging nitrogen until the Dissolved Oxygen (DO) in the tank reaches below $10 \%$ of the saturation level. Then air is reintroduced into the tank through the sparge at a known mass flow rate while the DO is monitored over time. This is monitored until the oxygen reaches close to $85 \%$ of the saturation level.

$$
\frac{d C_{A L}}{d t}=k_{L} a\left(\overline{C_{A L}}-C_{A L}\right)
$$

$\mathrm{C}_{\mathrm{AL}}$ is the dissolved oxygen concentration in percentage of saturation, $\mathrm{t}$ is time, $\mathrm{C}_{\mathrm{AL}}$ is the final $\mathrm{DO}$ concentration and $\mathrm{C}_{\mathrm{AL} 1}$ and $\mathrm{C}_{\mathrm{AL} 2}$ are the DO concentrations at times $t_{1}$ and $t_{2}$, respectively $[36,37]$.

For the configurations outlined in Table 1 steady-state method was used to give $\mathrm{k}_{\mathrm{L}}$ a values which serve as a quantitative comparison of the tanks. The volumetric mass transfer coefficient was determined at several points throughout the tank to give a volume-averaged mass 
Citation: Alok S, Immanuel G (2014) Effect of Different Impellers and Baffles on Aerobic Stirred Tank Fermenter using Computational Fluid Dynamics. J Bioprocess Biotech 4: 184 doi: 10.4172/2155-9821.1000184

Page 3 of 9

transfer coefficient for each configuration. This data was used to empirically derive the dimensionless correlations. It also assisted in assessing the mass transfer capabilities of specific impellers and baffles [38].

\section{Results and Discussions}

During this research work the effect of different types of impellers and baffles on mixing of aerobic stirred tank fermenter were studied.

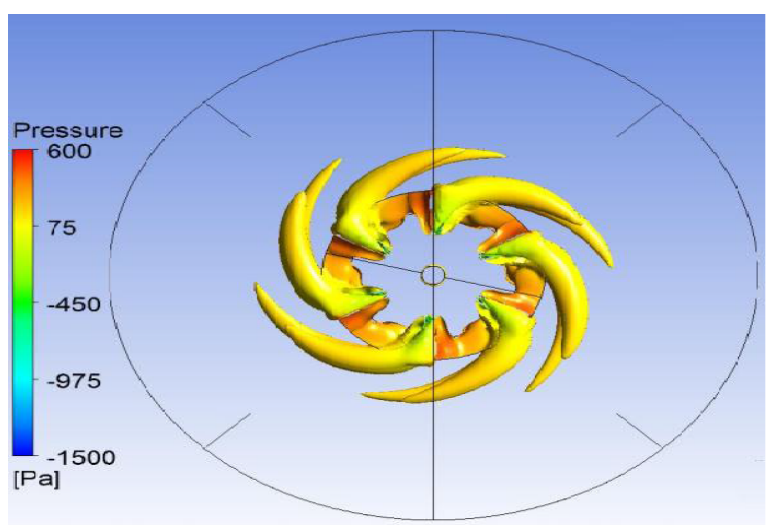

Figure 1: Simulation of Trailing Vortices by k- $\varepsilon$ model.

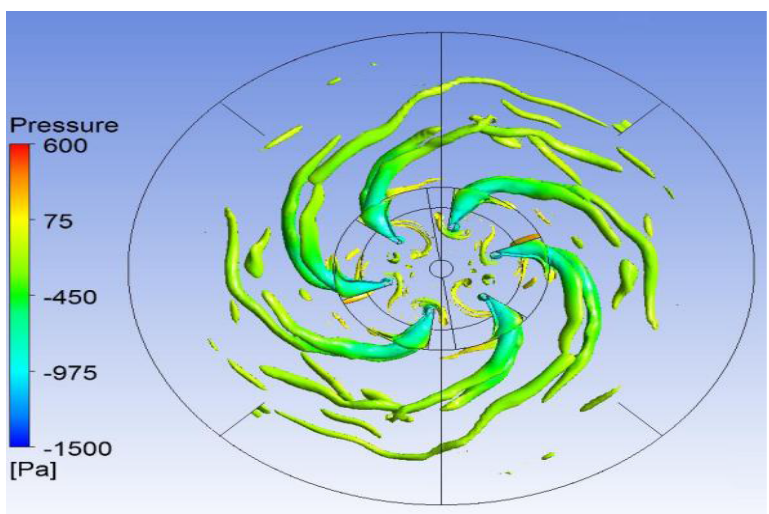

Figure 2: Simulation of Trailing Vortices by SAS SST.

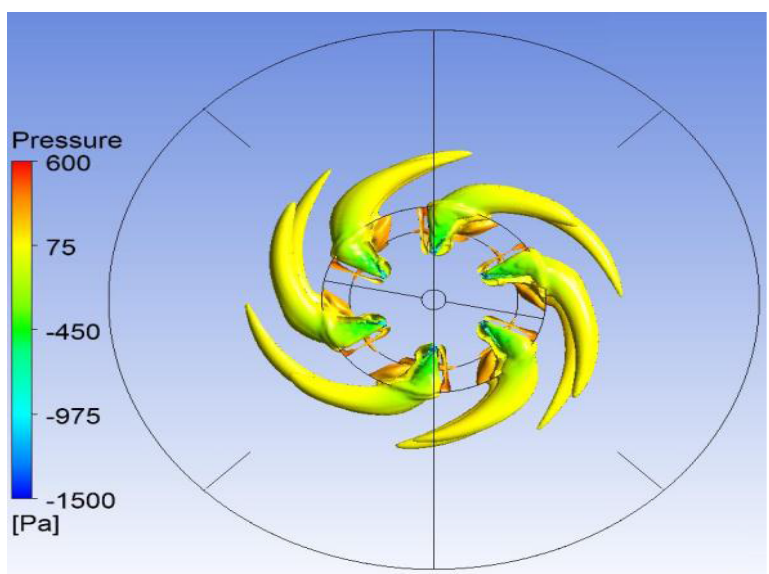

Figure 3: Simulation of Trailing Vortices by SST model.
This study involved the use of Computational Fluid Dynamics software packages i.e. Autodesk Simulation CFD and ANSYS FLUENT to obtain the simulations of the fluid mixing in Aerobic Stirred Tank Fermenter. The mathematical modelling was done by turbulence modelling and solved using MATLAB software package. The mixing time and mass transfer were also correlated to examine the performance of Aerobic Stirred Tank Fermenter.

\section{Effect of different types of Impellers and Baffles on Mixing}

First, the steady-state flow field was calculated and visually displayed to identify "dead zones" where the fluid was not moving or mixing very well. The pictures of the flow field gave information on how each impeller moves fluid through the tank. This aided in determining the effectiveness of impellers in their mixing capability. The second output from the CFD is a mixing time for each configuration [39]. After the steady-state formulation was calculated, the simulation was changed to a transient formation and a tracer fluid was introduced into the tank. The volume fraction of tracer fluid was monitored at several locations in the tank, according to Plate, and the mixing time was calculated as the time when $90 \%$ of homogeneity was reached. The effect of different Impellers and Baffles on Mixing has been studied and reviewed by Nurtuno T [37].

\section{Trailing Vortices}

The vortical structures in a flow were visualized in a number of different ways. Here the swirling strength has been used, based on the computation of the Eigen values of the velocity gradient tensor. A threshold value of 0.1 was found to be a good compromise between missing structures if the value was too high and masking the structures if the value was too low.

Unsteady two-equation models, such as k- $\varepsilon$ and SST, were found for excessively damping turbulence so that any detail of the turbulent structure (even on the larger scales) cannot be resolved directly. This is reflected by simulations generated using Autodesk Simulation CFD in Figure 1 for k- $\varepsilon$ model, Figure 2 for SAS SST model, and Figure 3 for SST model, which show that these models predict very small and hence dissipative trailing vortices with no secondary vortex motion apparent. Nevertheless, both the k- $\varepsilon$ and SST models predict the appearance of the pair of vortices, one vortex above and one vortex below the disk of the impeller that originate from behind each blade and trail out into the bulk of the flow [40-42].

\section{Turbulence Length}

In the $\mathrm{k}-\varepsilon$ and SST models, all turbulence scales are modelled through Reynolds-averaging, and hence a relatively large length-scale of turbulence was calculated using, as can be seen in Figure 4 and Figure 5. The length-scales of turbulence of up to $3 \mathrm{~mm}$ predicted by the $k-\varepsilon$ and SST models in the region of the impeller are similar to the experimental turbulence length-scales [43]. For the SAS-SST model, some details of the turbulence structures -the larger scale structurescan be directly resolved, while Reynolds averaging accounts for the smaller-scale turbulence structures. Figure 6 show that the SAS-SST model predicts longer trailing vortices and secondary vortex motions. The turbulence length-scales predicted by the SAS-SST model are much shorter than those predicted by the k- $\varepsilon$ and SST models, because the larger scale turbulence is now being directly resolved through the "LES" content of the model $[44,45]$. 
Citation: Alok S, Immanuel G (2014) Effect of Different Impellers and Baffles on Aerobic Stirred Tank Fermenter using Computational Fluid Dynamics. J Bioprocess Biotech 4: 184 doi: 10.4172/2155-9821.1000184

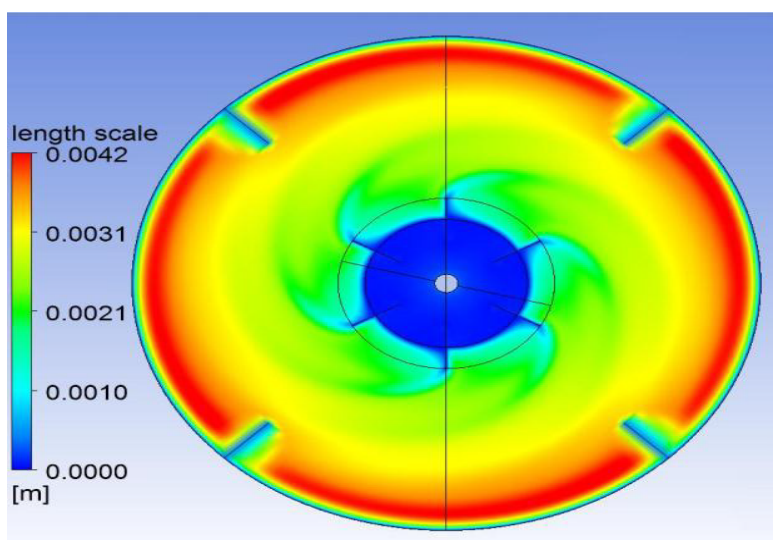

Figure 4: Simulation of Turbulence Length obtained by k- $\varepsilon$ model.

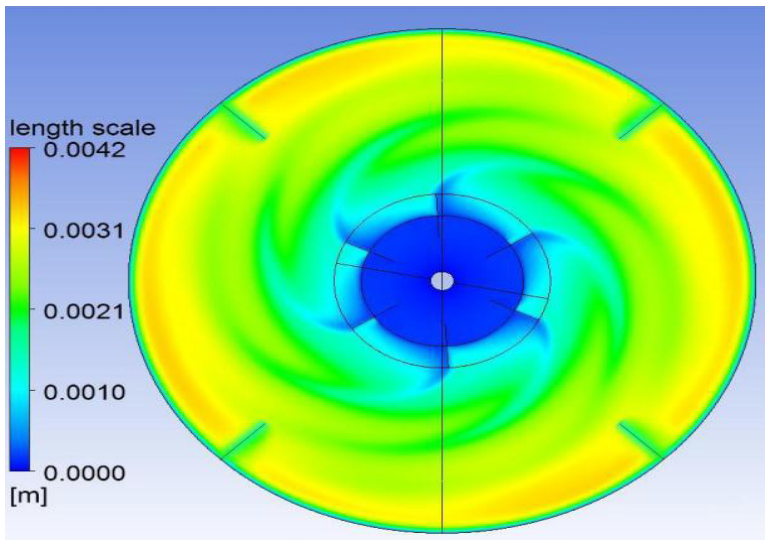

Figure 5: Simulation of Turbulence Length obtained by SST model.

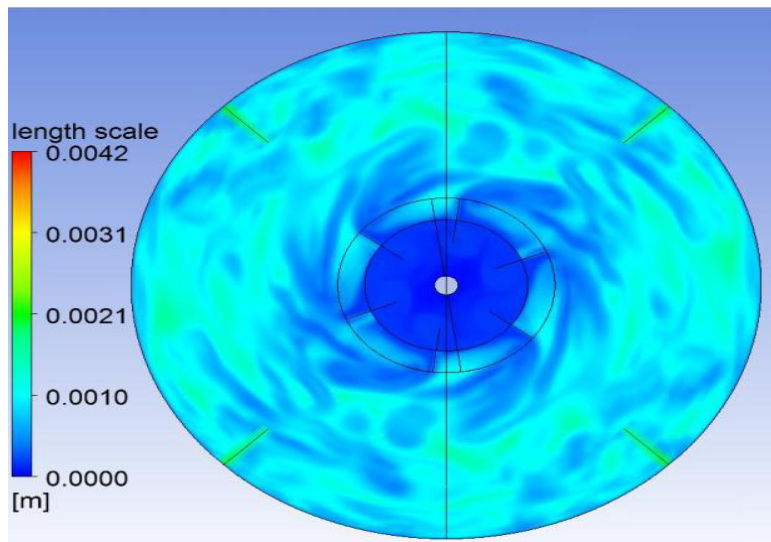

Figure 6: Simulation of Turbulence Length obtained by SAS SST model.

\section{CFD results of impellers and baffles obtained from ansys} fluent

The CFD results calculated in this study can be used to give a better understanding of mixing in stirred tanks, and how certain aspects of the tank produce better mixing. These pictures are a slice of the mid-plane of the tank and the arrows represent the direction of flow. The different colors of arrows represent faster moving fluid, where the length of the arrows represents the direction of the fluid moving at that point. Where the arrows are longer, the fluid is moving more in line with the mid-plane of the tank; where the arrows are shorter they are moving more perpendicular to the mid-plane of the tank. Figure 7 shows CFD

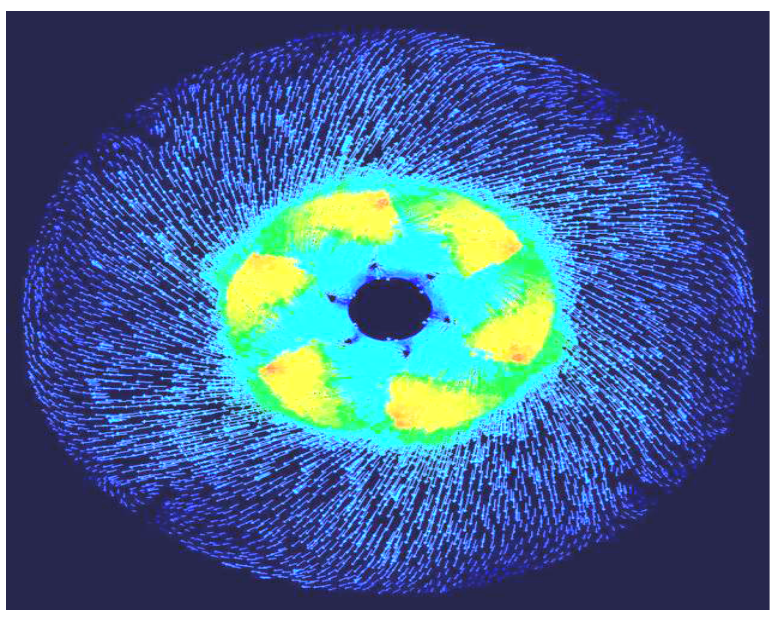

Figure 7: CFD Simulation for Rushton Impeller.

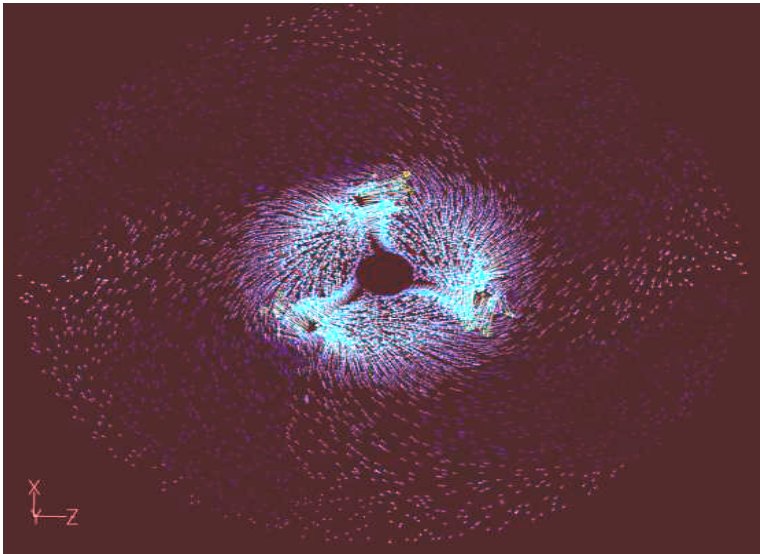

Figure 8: CFD Simulation for Marine Impeller.

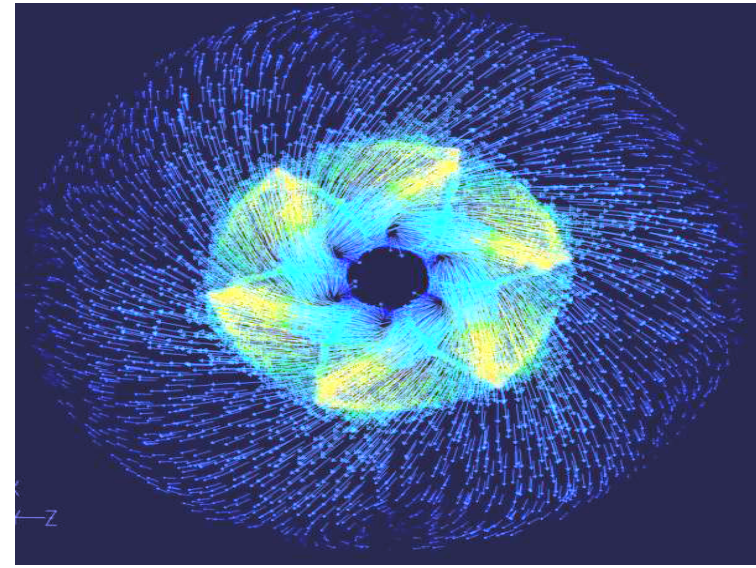

Figure 9: CFD Simulation for A320 Impeller. 
Citation: Alok S, Immanuel G (2014) Effect of Different Impellers and Baffles on Aerobic Stirred Tank Fermenter using Computational Fluid Dynamics. J Bioprocess Biotech 4: 184 doi: 10.4172/2155-9821.1000184

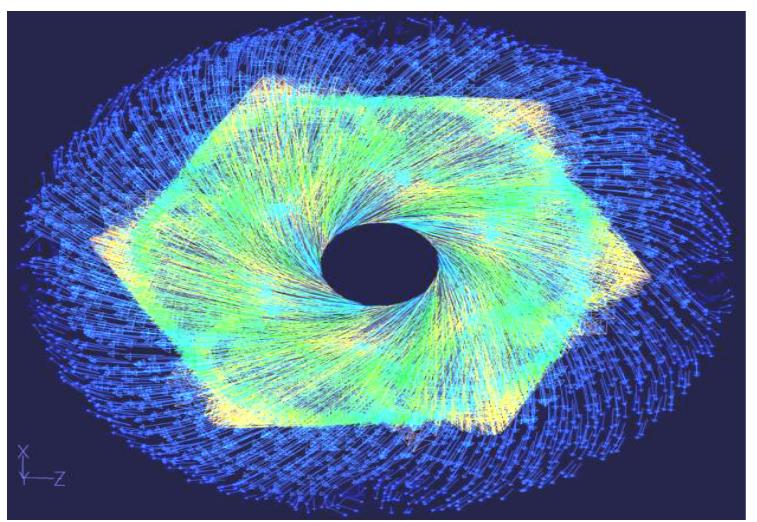

Figure 10: CFD Simulation for HE3 Impeller.

\begin{tabular}{|c|c|c|c|c|c|}
\hline \multirow{2}{*}{ S.No. } & Impeller & $\begin{array}{c}\text { Baffle } \\
\text { Configuration }\end{array}$ & $\begin{array}{c}\text { Baffle } \\
\text { Configuration }\end{array}$ & $\begin{array}{c}\text { Experimental } \\
\text { Determination of } \mathbf{k}_{\mathrm{L}} \mathbf{a}\end{array}$ & $\begin{array}{c}\text { CFD Steady } \\
\text { State Calculation } \\
\text { Time Calculation }\end{array}$ \\
\cline { 2 - 5 } & Rushton Impeller & Walled & Un walled & Yes & Yes \\
\hline 2 & Marine Impeller & Walled & Un walled & Yes & Yes \\
\hline 3 & A320 Impeller & Walled & Un walled & Yes & Yes \\
\hline 4 & HE3 Impeller & Walled & Un walled & Yes & Yes \\
\hline
\end{tabular}

Table 1: Impeller Tank Configuration and in which studies they were used.

\begin{tabular}{|c|c|c|c|}
\hline Impellers & $\left.\mathbf{T}_{\mathbf{m}} \mathbf{( s e c}\right)$ & $\mathbf{k}_{\mathbf{L}} \mathbf{a}$ at $\mathbf{4 0} \mathbf{~} \mathbf{p m}$ & $\mathbf{k}_{\mathbf{L}} \mathbf{a}$ at $\mathbf{7 0} \mathbf{~} \mathbf{p m}$ \\
\hline Rushton Impeller & 5.5 & 135 & 141 \\
\hline Marine Impeller & 7.9 & 72 & 78 \\
\hline A320 Impeller & 10.5 & 85 & 90 \\
\hline HE3 Impeller & 11.5 & 65 & 70 \\
\hline
\end{tabular}

Table 2: Average $k_{L}$ a values for different Impellers at Gas Flow Rate of $40 \mathrm{lpm}$ and $70 \mathrm{lpm}$.

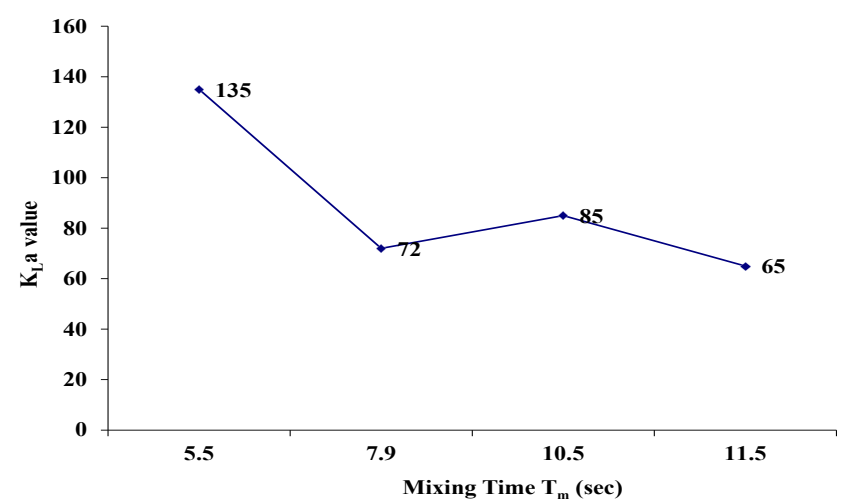

Figure 11: Average $\mathrm{K}_{\mathrm{L}}$ a values for different Impellers at Gas Flow Rate of $40 \mathrm{lpm}$.

Simulation for Rushton Impeller. Similarly, Figure 8, Figure 9 and Figure 10 show CFD Simulation for Marine Impeller, A320 Impeller and HE3 Impeller respectively [46-48].

\section{Correlation between Mixing Time Tm (sec.) and Volumetric} Mass Transfer Rate $k_{L} a(1 / h)$

The mixing times obtained in this study were compared to the experimental $\mathrm{k}_{\mathrm{L}} \mathrm{a}$ values to examine the possibility of a correlation. Table 2 shows the average $\mathrm{k}_{\mathrm{L}}$ a values for different Impellers at the Gas

Flow Rate of 40 and 70 liters per minute (lpm). The figures show the plot of $\mathrm{k}_{\mathrm{L}}$ a of each impeller versus the mixing time at the two flow rates $[49,50]$. Figure 11 and Figure 12 shows that non uniform $\mathrm{k}_{\mathrm{L}}$ a values were observed for all four Impellers with respect to Mixing Time $\left(\mathrm{T}_{\mathrm{m}}\right)$ at the Gas Flow Rate of $40 \mathrm{lpm}$ and $70 \mathrm{lpm}$. The correlation between Mixing Time and Volumetric Mass Transfer Rate were found to be more or less similar to those mentioned by Byung-Hwan Um (2007) (Table 3).

As seen in these figures the mixing times do not correlate to the experimentally determined $\mathrm{k}_{\mathrm{L}}$ a values. Due to this lack of correlation, gas flow rates of 20 and 10 liters per minute (lpm) were tested for all four Impellers. These additional tests are outlined in Table 3 and plotted in Figure 13 and Figure 14 [51-54].

\section{Effect of Impellers and Baffles on Turbulent Kinetic Energy and Turbulent Dissipation Rate with respect to Mixing Time}

The values of Turbulent Kinetic Energy $\mathrm{k}\left(\mathrm{m}^{2} / \mathrm{s}^{2}\right)$ and Turbulent Dissipation Rate $\varepsilon\left(\mathrm{m}^{2} / \mathrm{s}^{3}\right)$ were experimentally determined. The distribution of turbulent kinetic energy and dissipation rates as shown in Figures 15, 16, 17, 18, 19, 20, 21 and 22 are characteristic of the reactor geometry [55]. The turbulent $\mathrm{k}$ and $\varepsilon$ predicted by the various viscosity suspensions with the maximum values are found in the discharge region and a surrounding zone of relatively high turbulent kinetic energy. As expected, relatively high dissipation rates were found near the impellers. The values of $\mathrm{k}$ are close to zero with low dissipation rates elsewhere [56].

Figure 15 and 19 shows that there was uniform increase in Turbulent Kinetic Energy $(\mathrm{k})$ and Turbulent Dissipation Rate $(\varepsilon)$ with respect to Mixing Time in case of Rushton Impeller [57]. But, Figure 16, 17, 18, 20, 21 and 22 shows that there was fluctuations in Turbulent Kinetic Energy $(\mathrm{k})$ and Turbulent Dissipation Rate $(\varepsilon)$ with respect to Mixing Time in case of Marine Impeller, A320 Impeller and HE3 Impeller.

Since, the Turbulent Kinetic Energy (k) and Turbulent Dissipation 
Citation: Alok S, Immanuel G (2014) Effect of Different Impellers and Baffles on Aerobic Stirred Tank Fermenter using Computational Fluid Dynamics. J Bioprocess Biotech 4: 184 doi: 10.4172/2155-9821.1000184

Page 6 of 9

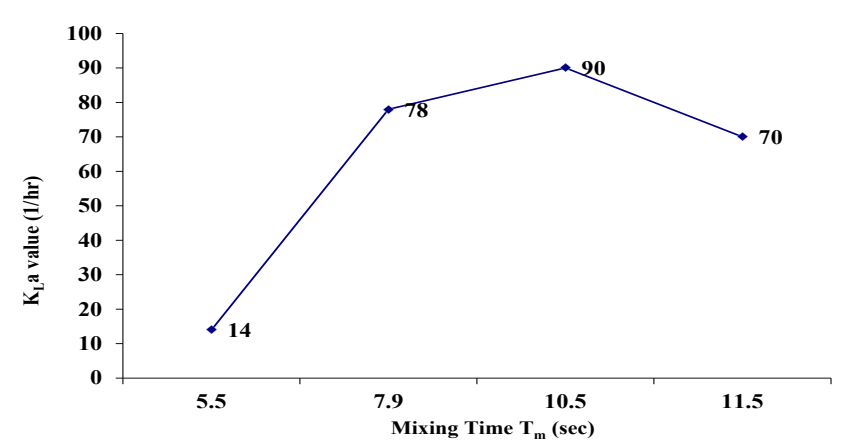

Figure 12: Average $\mathrm{K}_{\mathrm{L}}$ a values for different Impellers at Gas Flow Rate of $70 \mathrm{lpm}$.

\begin{tabular}{|c|c|c|c|}
\hline Impellers & $\mathbf{T}_{\mathbf{m}}(\mathbf{s e c})$ & $\mathbf{k}_{\mathbf{L}} \mathbf{a}$ at $\mathbf{2 0} \mathbf{~} \mathbf{p m}$ & $\mathbf{k}_{\mathbf{L}} \mathbf{a}$ at $\mathbf{1 0} \mathbf{~} \mathbf{p m}$ \\
\hline Rushton Impeller & 16.0 & 56 & 79 \\
\hline Marine Impeller & 14.7 & 67 & 87 \\
\hline A320 Impeller & 10.2 & 63 & 93 \\
\hline HE3 Impeller & 9.1 & 71 & 112 \\
\hline
\end{tabular}

Table 3: Additional $k_{\llcorner}$a Testing performed at Gas Flow Rate of $20 \mathrm{lpm}$ and $10 \mathrm{lpm}$.

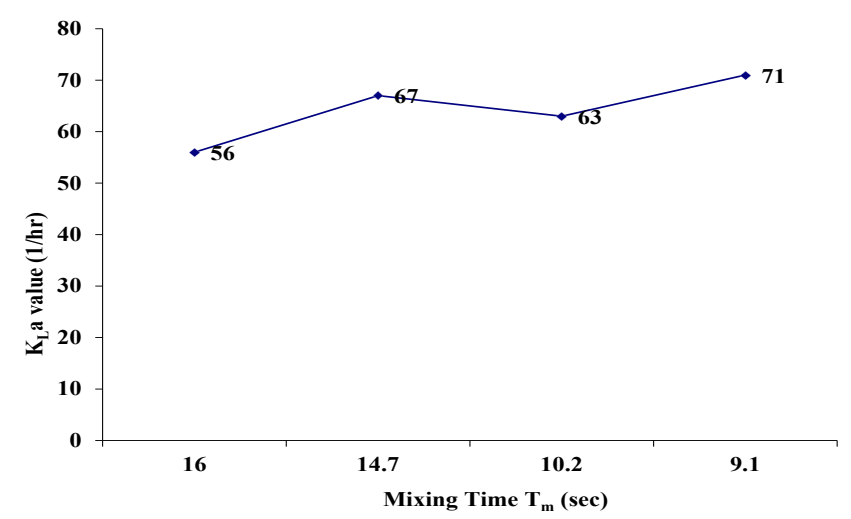

Figure 13: Additional $\mathrm{K}_{\llcorner}$a Testing performed at Gas Flow Rate of $20 \mathrm{lpm}$.

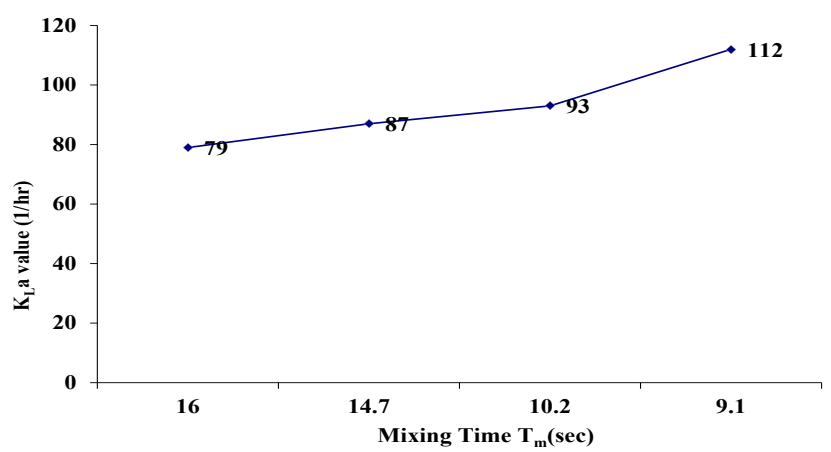

Figure 14: Additional $\mathrm{K}_{\llcorner}$a Testing performed at Gas Flow Rate of $10 \mathrm{lpm}$.

Rate $(\varepsilon)$ were used to represent Volumetric Mass Transfer Rate. The data from these figures indicated that Mass Transfer was very efficient whenever the Rushton Impeller was used while Marine Impeller, A320 Impeller and HE3 Impeller were somewhere inefficient as compared to latter [58].
These data also indicated that Rushton Impeller was indeed more efficient for Mass Transfer in Aerobic Stirred Tank Fermenter when used with walled baffles instead of unwalled baffles [35]. The other three impellers i.e. Marine Impeller, A320 Impeller and HE3 Impeller were not as much efficient as Rushton Impeller to provide efficient Mass Transfer in Aerobic Stirred Tank Fermenter with walled as well as unwalled baffle. The configuration of different impellers with baffles is mentioned in Table 1 [17].

\section{Conclusion}

Flow pattern calculations for potential operating conditions of Rushton six blade Impeller, Marine Impeller, A320 Impeller and HE3 Impeller in the ellipsoidal bottom tank have been performed to assess mixing behavior. The trailing vortices and turbulence length modeled by k- $\varepsilon$ model, SST model and SAS SST model were used to understand

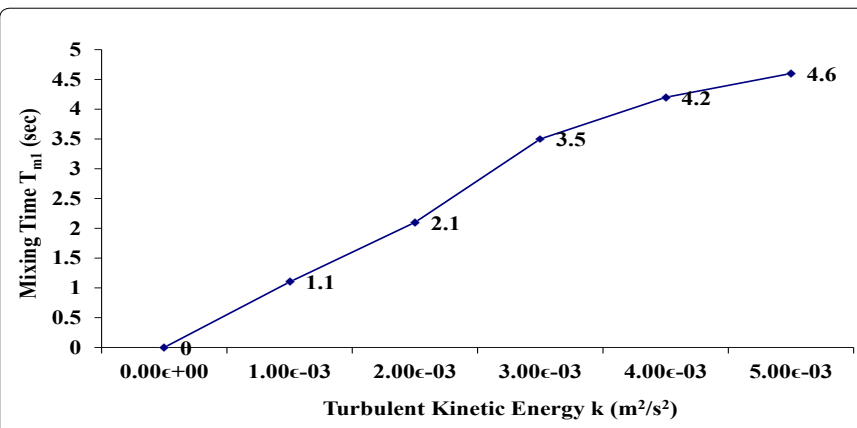

Figure 15: Turbulent Kinetic Energy $\left(\mathrm{m}^{2} / \mathrm{S}^{2}\right)$ for different Tank Diameter $\left(D_{t}\right)$ and Mixing Time $\mathrm{T}_{\mathrm{m} 1}$ for Rushton Impeller.

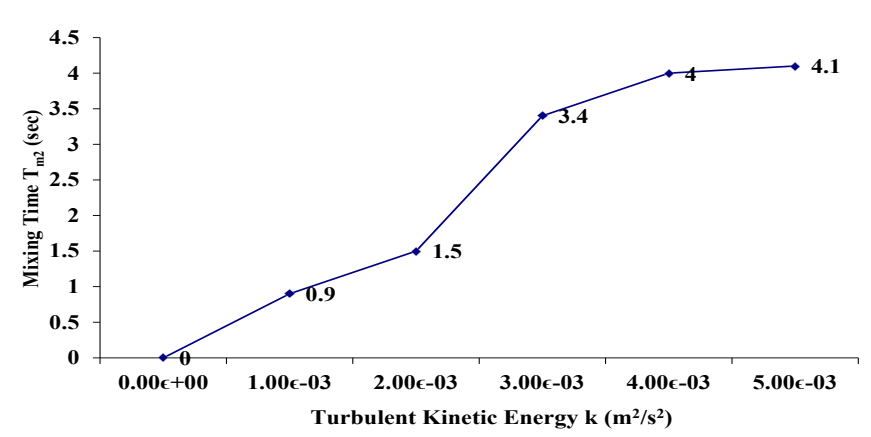

Figure 16: Turbulent Kinetic Energy $\left(\mathrm{m}^{2} / \mathrm{S}^{2}\right)$ for Tank Diameter $\left(D_{t}\right)$ and Mixing Time $\mathrm{T}_{\mathrm{m} 2}$ for Marine Impeller.

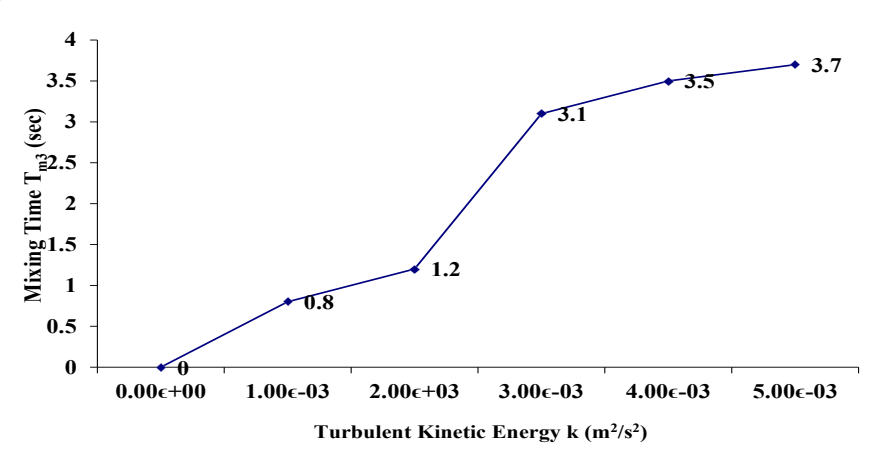

Figure 17: Turbulent Kinetic Energy $\left(\mathrm{m}^{2} / \mathrm{S}^{2}\right)$ for Tank Diameter $\left(D_{t}\right)$ and Mixing Time $T_{m 3}$ for $\mathrm{A} 320$ Impeller. 
Citation: Alok S, Immanuel G (2014) Effect of Different Impellers and Baffles on Aerobic Stirred Tank Fermenter using Computational Fluid Dynamics. J Bioprocess Biotech 4: 184 doi: 10.4172/2155-9821.1000184

Page 7 of 9

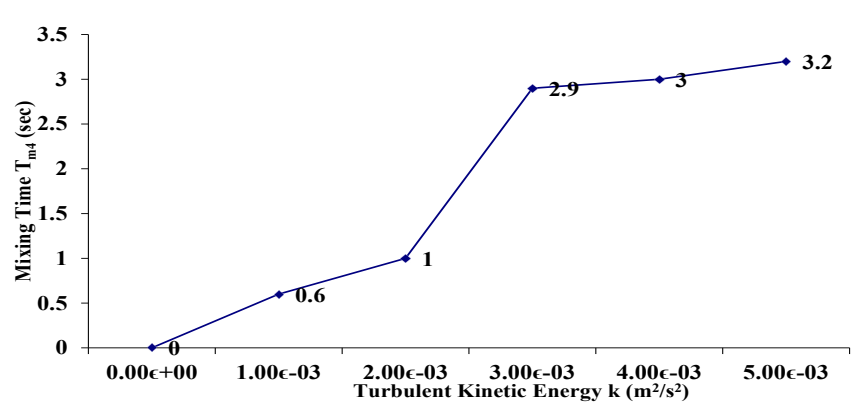

Figure 18: Turbulent Kinetic Energy $\left(\mathrm{m}^{2} / \mathrm{S}^{2}\right)$ for Tank Diameter $\left(D_{t}\right)$ and Mixing Time $\mathrm{T}_{\mathrm{m} 4}$ for HE3 Impeller.

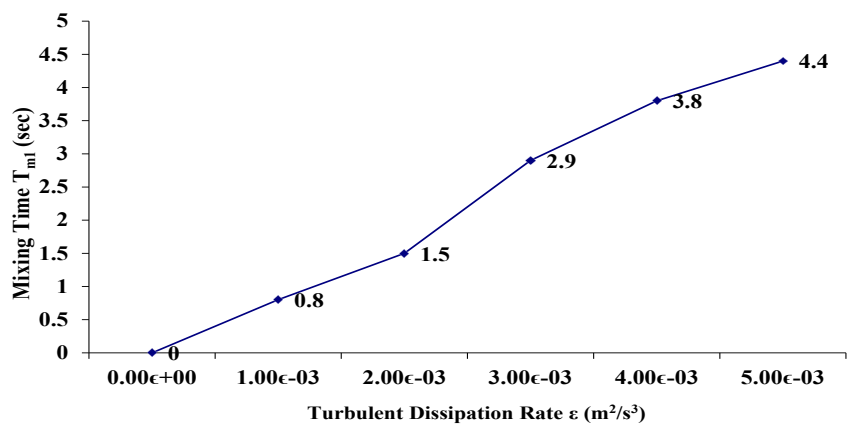

Figure 19: Turbulent Dissipation Rate $\left(\mathrm{m}^{2} / \mathrm{S}^{2}\right)$ for Tank Diameter $\left(D_{t}\right)$ and Mixing Time $T_{m 1}$ for Rushton Impeller.

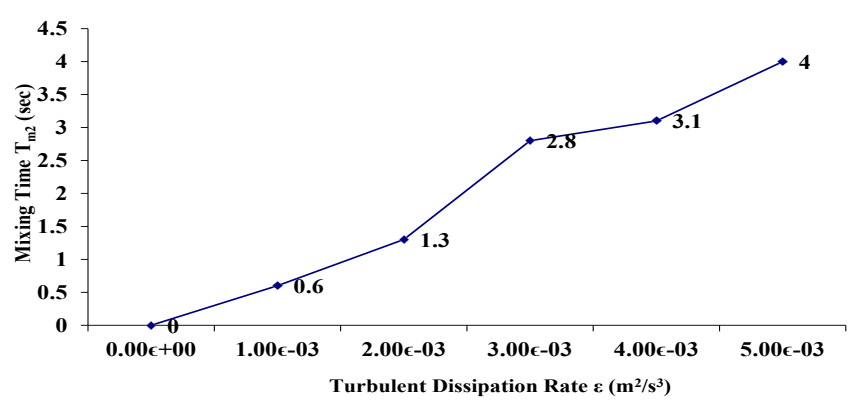

Figure 20: Turbulent Dissipation Rate $\left(\mathrm{m}^{2} / \mathrm{S}^{3}\right)$ for Tank Diameter $\left(D_{t}\right)$ and Mixing Time $T_{m 2}$ for Marine Impeller.

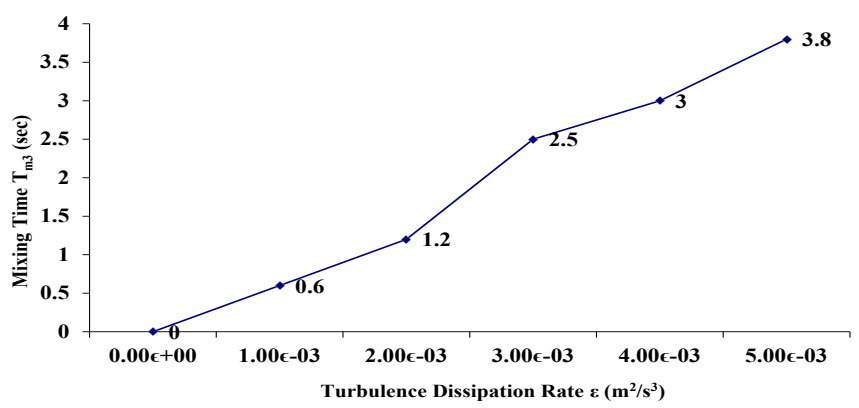

Figure 21: Turbulent Dissipation Rate $\left(\mathrm{m}^{2} / \mathrm{S}^{3}\right)$ for different Tank Diameter $\left(D_{t}\right)$ and Mixing Time $T_{m 3}$ for A320 Impeller.

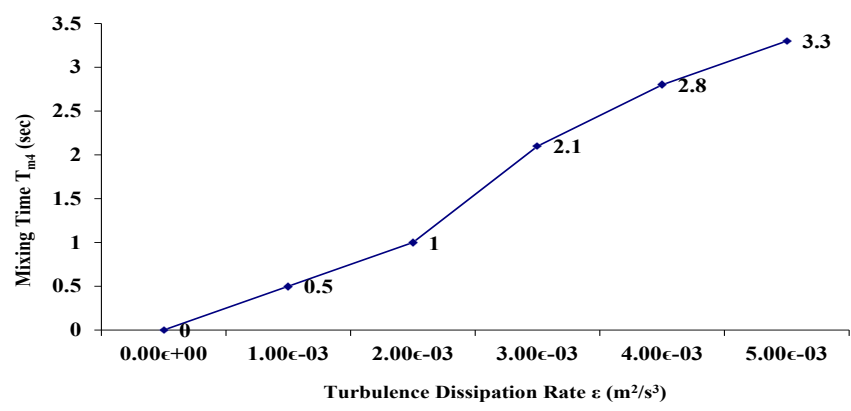

Figure 22: Turbulent Dissipation Rate $\left(\mathrm{m}^{2} / \mathrm{S}^{3}\right)$ for different Tank Diameter $\left(\mathrm{t}_{1}\right)$ and Mixing Time $\mathrm{T}_{\mathrm{m} 4}$ for HE3 Impeller.

the effect of Impeller and Baffles. Among these Impellers Rushton Impeller was the most efficient. The modeling results were used determine acceptable agitator speeds and tank liquid levels to ensure suspension of solid particles deposited during high solid fermentation.

A few important observations with regard to the effect of fluid viscosity on fermentation suspension in the laminar flow regime have been made in this work. The main interest was axial and mixed-flow pattern of impellers since they are the most important considered for viscous suspension mixing. It was found that the axial flow component for these impellers was suppressed on the bottom of the tank, such that overall flow was predominantly radial. Specifically, this relatively weak distribution of axial velocities at the bottom of the tank may cause the solid particles to stay around the bottom of the tank. This condition becomes more significant with increased solid concentration.

The simulation shows that there is a potential for slow flow or stagnant fluid between the bottom of tank and the fermentor wall and also above the top impeller. In an aerobic fermentation, both of these regions could become depleted of oxygen. High shear rates and energy dissipation rates could be found near both impellers. In all of fermentations, high shear and energy dissipation regions could deactivate the microorganism.

From the experimental $\mathrm{k}_{\mathrm{L}}$ a studies we see that for a 197 liter tank with a 2:1 height to diameter ratio, 6-blade Rushton impeller used with the walled baffles creates the best conditions for mass transfer. The axial flow impellers so not seem to have any advantage, or disadvantage over the radial flow impellers. Numerically calculated mixing times do not correlate with mass transfer for the gas flow rates used by this STR and thus can only be used to give information on mixing.

\section{References}

1. Ali HKhQ, Zulkali MMD (2011) Design Aspects of Bioreactors for Solid-State Fermentation: A Review.Chem Biochem Eng 25: 255-266.

2. Ameur H, Bouzit M, Helmaoui M (2011)Numerical study of fluid flow and power consumption in a stirred vessel with a Scaba 6SRGT impeller. Chemical and Process Engineering 32: 351-366.

3. Aubin J, Fletcher DF Xuereb C (2004) Modeling Turbulent Flow in Stirred Tanks with Computational Fluid Dynamics: The Influence of the Modeling Approach Turbulence Model \& Numerical Scheme.Experimental Thermal and Fluid Science 28: $431-445$

4. Bakker Andre (2006) Fermenter Specific Modeling Issues.

5. Benz GT (2003) Optimize Power Consumption in Aerobic Fermenters. CEP Magazine, 23-28.

6. Benz GT (2004) Sizing Impellers for Agitated Aerobic Fermenters. CEP Magazine, 18-24. 
Citation: Alok S, Immanuel G (2014) Effect of Different Impellers and Baffles on Aerobic Stirred Tank Fermenter using Computational Fluid Dynamics. J Bioprocess Biotech 4: 184 doi: 10.4172/2155-9821.1000184

7. Ariffin MAB (2010) Design, Construction and Commissioning of Bioreactor Experimental Rig to Measure $\mathrm{K}_{\mathrm{L}} \mathrm{a}$ of Oxygen in Newtonian Fluid. Project Report. Universiti Malaysia Pahang.

8. Blakerough N (2012) Fundamentals of Fermenter Design, Department of Chemical Engineering, University of Birmingham, UK.

9. Elqotbi M, Montastruc L, Vlaev SD, Nikov I (2004) CFD simulation of gluconic acid production in a stirred gas-liquid fermenter.

10. Bourdichon F, Casaregola S, Farrokh C, Frisvad JC, Gerds ML, et al. (2012) Food fermentations: microorganisms with technological beneficial use. Int $J$ Food Microbiol 154: 87-97.

11. Breedveld P, Couenne F,Jallut C, Maschke B, Tayakout M (2003) Model of a Continuous Stirred Tank Reactor using Bond Graph Formalism. Biotechnol Bioeng 1009-1105.

12. Chain FB, Paladino S, Callow DS, Ugolini F, Vander Sluis J (1952) Studies on aeration. I. Bull World Health Organ 6: 73-97.

13. Charles Marvin, Wilson Jack (1994) Fermentation Design

14. Chisti Y, Moo-Young M (1993) Aeration and mixing in vortex fermenters. J Chem Technol Biotechnol 58: 331-336

15. Dale MC, Zhou C (1995) Design of a Pilot Scale Continuous Stirred Ethanol Reactor Separation with Solvent Absorption \& Extractive Distillation. CoFE 1-6.

16. Angelique D, Delvigne F, Collignon ML, Crine M, Thonart $P$, et al. (2010) Development of compartment model based on CFD simulation for description of mixing in biorectors. Biotechnol Agron Soc Environ 14: 517-522.

17. Dutta R (2008) Fundamentals of Biochemical Engineering, Amity Institute of Biotechnology

18. Egedy A, Marcus DS, Dominique A (2011) Application of Models with Different Complexity for a Stirred Tank Reactor. Hungarian Journal of Industrial Chemistry 39: 335-339.

19. Ein-Mozaffari F, Upreti SR (2010) Investigation of mixing in shear thinning fluids using computational fluid dynamics. Intech Open.

20. Gaden EL Jr (2000) Fermentation process kinetics. Reprinted from Journal of Biochemical Microbiological Technology and Engineering VOI. 1, No. 4 Pages 413-29 (1959). Biotechnol Bioeng 67: 629-635

21. Gill NK, Appleton M, Baganz F, Lye GJ (2008) Quantification of power consumption and oxygen transfer characteristics of a stirred miniature bioreactor for predictive fermentation scale-up. Biotechnol Bioeng 100: 11441155.

22. Gimbun J, Radiah ABD, Chuah TG (2004) Bioreactor design via spreadsheet-a study on the monosodium glutamate (MSG) process. Journal of Food Engineering 64: 277-283.

23. Guha D, Dudukovic MP, Ramachandran PA, Mehta S, Alvare J (2004) CFD based Compartmental Modelling of Single Phase Stirred Tank Reactors. AIChE Journal 52: 1836-1846.

24. Hristov HT, Mann R, Lossev V, Vlaev SD (2004)A Simplified CFD for Threedimensional Analysis of Fluid Mixing, Mass Transfer and Bioreaction in a Fermenter Equipped with Triple Novel Geometry Impellers. Food and Bioproducts Processing 82: 21-34.

25. Hugo A,Mork M, Grislingas A (2003) Stirred Tank Reactor, Reactor Technology

26. Karcz J, Siciarz R, Bielka I (2004) Gas Hold-Up in a Reactor with Dual System of Impellers. Chem Pap 58: 404-409.

27. Karimi A, Golbabaei F, Mehrnia MR, Neghab M, Mohammad K, et al. (2013) Oxygen mass transfer in a stirred tank bioreactor using different impeller configurations for environmental purposes.Iranian J Environ Health Sci Eng $10: 6$.

28. Kaushal P, Sharma HK (2012) Concept of Computational Fluid Dynamics (CFD) and its Applications in Food Processing Equipment Design.J Food Process Technol 3:138.

29. Kokoo R, Narataruksa P, Pana-Suppamassadu K, Tungkamani S (2008) Determination of optimum rotational speed of heterogeneous catalytic reactor using computational fluid dynamic. Songlanakarin J Sci Technol 755-760.

30. Kozma L, Nyeste L, Szentirmai A (2006) Optimization Problems of Fermenter Aeration-Agitation System. Hungarian Journal of Industrial Chemistry34: 35-39.
31. Kunik S, Mudroncik D, Kopcek M, Stremy M (2007) Virtual and Analogue Mode of a Continuous Stirred Tank Reactor. 16th Int. Conference Process Contro $1-4$.

32. Le Roux JMW, Purchas K, Nell B (1986) Refrigeration requirement for Precooling \& Fermentation Control in Wine Making.S Afr J Enol Vitic 7: 6-13.

33. McNeil B, Harvey LM (2008) Practical Fermentation Technology. John Wiley \& Sons, USA.

34. Moilaneu P, Laakkonen M, Aittamaa J (2005) Modelling fermenters with CFD. European Symposium on Computer Aided Process Engineering-15.

35. Montante G, Coroneo M, Francesconi JA, Paglianti A, Magelli F (2012) CFD Modelling of a Novel Stirred reactor for the Bioproduction of Hydrogen. 14th European Conference on Mixing 311-316.

36. Nikhil TR (2007) Software Design of Stimulating Microbial Process in Bioreactor. Environmental Informatics Archive 5.

37. Nurtono T, Nirwana WOC, Anwar N, Nia SM, Widjaja A, et al. (2012) A CFD Study into a Hydrodynamic Factor that affects a Biohydrogen Production Process in a Stirred Tank Reactor. Procedia Engineering 50: 232-245

38. Ochieng Aoyi, Onyango Maurice S (2010). CFD Simulation of Solid Suspension in Stirred Tanks.

39. Patarinska T, Trenev V, Popova S (2010) Software Sensors Design for a Class of Aerobic Fermentation Processes. International Journal of Bioautomation 99118.

40. Ranade VV, Tayalia Y, Krishnan H, (2002) CFD Predictions of Flow near Impelle Blades in Baffled Stirred Vessels. Chemical Engineering Communications 189: 895-922.

41. Ranade VV, Perrard M, Le SN, Xuereb C, Bertrand J (2002) Trailing vortices of Rushton turbines.Chemical Engineering Research and Design 79: 3-12.

42. Saarela U, Kauko L, Esko J (2003) Modeling of a Fed Batch Fermentation Process.

43. Sahlin Peter (1999) Fermentation as a Method of Food Processing. Production of Organic Acids pH-development \& Microbial Growth in Fermenting Cereals.

44. Vanea SM, Lena BE, Rolland M (2012) Numerical CFD Simulation of a Batch Stirred Tank Reactor with Stationary Catalytic Basket. Chemical Engineering Journal 207: 596-606.

45. Madhavi SV, Ranade VV (2012) Computational Fluid Dynamics Modelling of Solid Suspension in Stirred Tanks. Current Science 102: 1539-1551.

46. Shukla S, Nayak D, Khan HS (1998) Numerical prediction of flow fields in baffled stirred vessels: a comparison of alternative modeling approaches. Chemical Engineering Science 53: 3653-3684.

47. Srinophakun T, Jessada J (2000) Computational Fluid Dynamics for Mixing Behaviour in Bakers' Yeast Fermentation.

48. Stanbury PF, Hall S,Whittakar A (1999) Principles of Fermentation Technology ( $2^{\text {nd }}$ edition)

49. Sungkorn R, Derksen JJ, Khinast JG (2012) Modelling of Aerated Stirred Tanks with Shear thinning Power Law Liqiud. International Journal of Heat and Fluid Flow 36: 153-166.

50. UdayaBhaskar RR, Goplakrishnan S, Ramaswamy E (2002) CFD Analysis of Turbulence Effect on Reaction in Stirred Tank Reactor.

51. Vamsi KK, Boraste A, Jhadav A (2009) Construction \& Standardization of Bioreactor for Production of Alkaline Protease from Bacillus licheniformis. International Journal of Microbiology Research 1: 32-44.

52. Verschuren IL (2001) Feed Stream Mixing in Stirred Tank Reactor. Int of Biochem Eng 44: 56-72.

53. Walter PH (2005) Fermentation based manufacturing processes \& fermentation products. GMFFTL: $1-50$

54. Wan TEL, Kumar P, Samyudia Y (2011) Computational Fluid Dynamics of Mixing in Aerated Bioreactors. International Conference on Biology, Environment \& Chemistry.

55. Warfvinge P (2012) Reactor Calculation, The continuous Flow, Stirred Tank Reactor CSTR, Department of Chemical Engineering, Lund University. 
Citation: Alok S, Immanuel G (2014) Effect of Different Impellers and Baffles on Aerobic Stirred Tank Fermenter using Computational Fluid Dynamics. J Bioprocess Biotech 4: 184 doi: 10.4172/2155-9821.1000184

Page 9 of 9

56. Lin X1, Liu H, Zhu F, Wei X, Li Q, et al. (2012) Enhancement of biodesulfurization by Pseudomonas delafieldii in a ceramic microsparging aeration system. See comment in PubMed Commons below Biotechnol Lett 34: 1029-1032.

57. Zdenka P, Roman P (2009) Modeling \& Simulation of Dry Anaerobic Fermentation. 24 European Conference on Modelling\& Simulation.
58. Zhou Z, Mirac N, Iminia F, Goniya J (2013) Experimental Study \& CFD Simulation of Mass Transfer Characteristics of a Gas-Induced Pulsating Flow Bubble Column. Chem Biochem Eng 27: 167-175. 